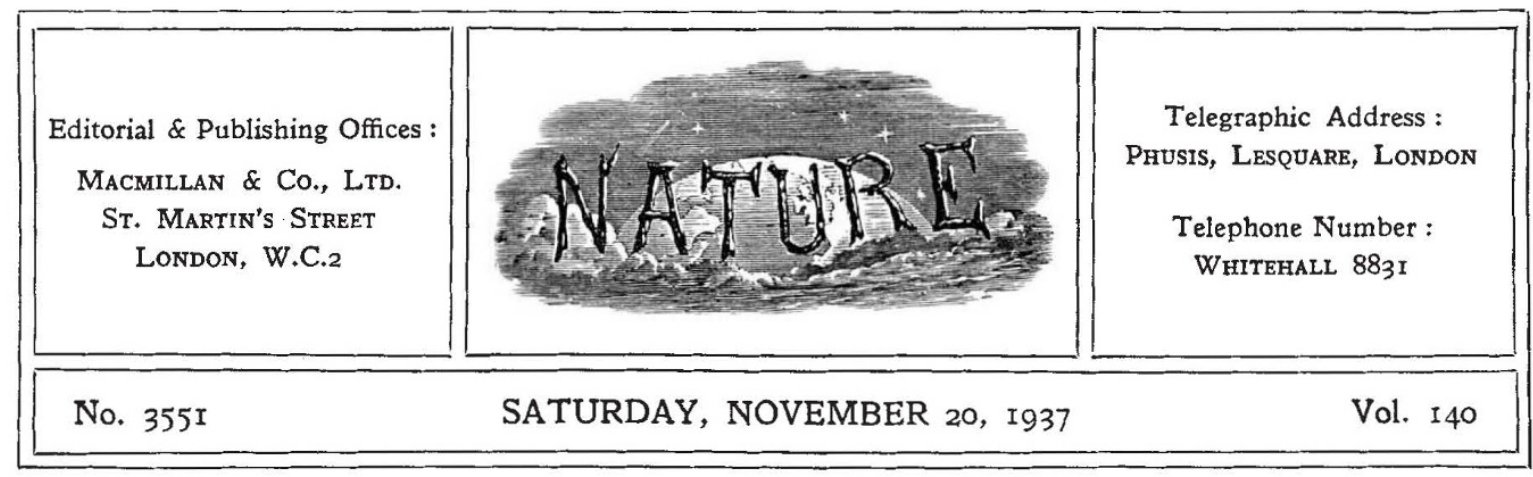

\title{
Social Aspects of Nutritional Science
}

$T^{1}$ HOUGH there is still a tendency among certain people to deplore the passing of the "good old days", it has to be acknowledged that during the past century and a half the lot of the poorer sections of the populations of western Europe has been enormously improved. In the past, war, famine and pestilence have decimated many countries; to-day, in Europe, famine is the exception and many types of pestilence have been already almost forgotten, although the widespread occurrence of infectious diseases, especially influenza in pandemic form, yet offers many problems for preventive medicine. The advance in public health and well-being; strikingly shown by the fall in the death-rate and the extension in the expectation of life of the individual, was made possible by the advances in sanitation and medical knowledge, and the improvement in the social conditions of the lower-income groups was due to the rapid growth of wealth, which resulted mainly from the advances in scientific knowledge and its application. The awakening of the social conscience of the community has frequently played no mean part in these advances.

In spite, however, of the improvement in the health of the people, it is only comparatively recently that it has been realized what an important part nutrition plays in maintaining health : with increasing wealth, diet has become more abundant and more varied, but the improvements in the past have been largely the result of the unconscious and instinctive groping of men for a better and more abundant life. To-day, medical science can state, within limits, what is a good and what is a bad diet: therefore, it is possible from dietary studies to determine whether people are eating the right kinds of food in sufficient quantities.
Further, our knowledge of the results of consuming ill-balanced diets has increased to the extent of enabling us to say, in many cases, from a clinical examination, whether malnutrition is present and what particular element in the diet is lacking, even apart from the obvious occurrence of what are now known as the frank 'deficiency diseases', such as scurvy, rickets or beriberi.

Perusal of the recent report of the League of Nations on nutrition, reviewed elsewhere in this issue, shows, however, that in spite of the general improvement in the social conditions of the poorer sections of the communities of western Europe in recent decades, much malnutrition still exists, even in the richer countries. The evidence is both clinical and economie: dietary and income surveys have shown that among the lowest-income groups it is simply impossible for the members to obtain a proper diet, since the family income is insufficient! Nutrition policy, therefore, must be directed both to educating people in the elements of correct dietetics, and also, which is even more important, to enabling everyone to make full use of our present knowledge, by bringing the foodstuffs essential to health and physical development within reach of all sections of the community. No campaign for improving physical fitness can succeed when nutrition is at fault.

What, then, does improved nutrition imply? Usually an increased consumption of animal protein, milk, eggs, 'fat' fish, green vegetables and fresh fruits, with a decreased consumption of cereals : in other words, a decrease in the consumption of the purely energy-bearing foods, and an increase in that of the so-called "protective" foods, which are in general the more expensive. Dietary surveys have shown that with increasing 
income, more of the protective foods are consumed ; the problem is therefore largely economic-how to increase the incomes of the more poorly paid sections of the community, or, alternatively, how to reduce the price of the protective foods, which comes to the same thing. One objection, that the shift in consumption will cause distress among many agriculturists, is shown in the League of Nations report to be of no weight. For many years agriculture has been adapting itself to just such a shift in consumption, which has occurred with the general increase in wealth of many countries ; moreover, cereals formerly produced for human consumption can also be used as animal feed when the demand for meat and milk increases.

It is impossible to-day for Governments to divest themselves of responsibility for the nutrition of their peoples; nutrition should be considered to-day the most important of all the social services.
Education in the correct principles of nutrition and avoidance of policies which may prevent the full use of adequate diets should be the foremost considerations of legislators as steps in the improvement of the well-being and health of their peoples. It must be emphasized that the problems are indeed complex; thus a simple reduction in the price of food may benefit the urban consumer but bring ruin and malnutrition to the agricultural producer.

The League's report on nutrition should be in the hands of all who have the welfare of the people at heart, especially those entrusted with the direction of policy. If Governments can achieve for their peoples adequate levels of food consumption, further progress, in no way less spectacular than that achieved during the nineteenth century, can be made in increasing the quantity and raising the quality of human life.

\section{Logic and Empiricism}

\section{Actes du Congrès International de Philosophie} scientifique, Sorbonne, Paris, I935

1: Philosophie scientifique et empirisme logique. Pp. 81. 12 francs. 2: Unité de la science. Pp. 77. 12 francs. 3 : Langage et pseudo-problèmes. Pp. 60. 10 francs. 4: Induction et probabilité. Pp. 65. 10 francs. 5 : Logique et expérience. Pp. 80. 12 francs. 6 : Philosophie des mathématiques. Pp. 85.12 francs. 7 : Logique. Pp. 73.10 francs. 8: Histoire de la logique et de la philosophie scientifique. Pp. 92. 12 francs. (Actualités scientifiques et industrielles, 388-395.) (Paris : Hermann et Cie., 1936.)

GCIENTIFIC philosophy may be in a state of $S$ flux in its details, but there is one guiding principle which seems to give at least a unity of purpose to the numerous schools of thought which have made logic their chief interest. This principle requires that the reconstruction of our knowledge should be made on the basis of experience alone, free from anthropomorphic addi. tions, and by means of a unified scientific language shaped out of logical syntax. Let it be said at once that few thinkers would dispute the fundamental importance of this principle, provided that it is interpreted in a liberal spirit. It seems, however, that the more vocal logicians of to-day deliberately restrict experience to sense-data alone, thus leaving out those no less important aspects of experience which refer to moral, æsthetic, mystical and religious values. Without arguing the point as to whether it is possible or not to achieve a complete synthesis of our knowledge with these initial restrictions on the meaning and acception of experience, it can be admitted that this narrow interpretation of the guiding principle of scientific philosophy has aroused the enthusiasm of all those important thinkers who have adopted Russell's motto that logic is the great liberator of the mind. The Paris Congress of Scientific Philosophy is the first result of their intellectual crusade, though some of its meetings were tempered by the presence of more traditional thinkers.

Unity of purpose, however, is not incompatible with difference of interests ; and it is not one of the least remarkable aspects of the vitality of logic that it has developed in so many directions. The variety of the papers under review bear witness to this statement. Thus, the first fascicule, devoted to "Philosophie scientifique et empirisme logique", contains a series of declarations of faith in logical empiricism by some leaders of the movement such as Russell, Frank, Reichenbach, Carnap, Neurath, Enriques, Morris, Wiesner, Chwistek, Kotarbinski, Ajdukiewicz and Prof. Louis Rougier, who organized the Congress so ably and supervised the publication of the papers. 